\title{
Impactos ecológicos do manejo comunitário de recursos naturais em comunidades ribeirinhas de várzea e terra firme na região de Tefé, AM
}

Ana Cristina Mendes de Oliveira - Doutora em Desenvolvimento Sustentável do Trópico Úmido pela UFPA. Professora no Programa de Pós-Graduação em Zoologia do convênio MPEG/UFPa e Pesquisadora do Instituto de Pesquisa Ambiental da Amazônia (IPAM).

Daniel Curtis Nepstad - Doutor. em Ecologia de Florestas Tropicais pela Yale University e professor da UFPA, Pesquisador do Instituto de Pesquisa Ambiental da Amazônia

David Gibbis McGrath - Doutor em Geografia pela University of Wisconsin - Madison, pesquisador do Woods Hole Research Center e professor/pesquisador da UFPA.

Alexandre Fernandes da Silva - Pós Graduado Programa de Pós-graduação em Zoologia (UFPA/MPEG).

\section{Resumo}

As bases teóricas do conservacionismo e do preservacionismo são discutidas neste trabalho de pesquisa, baseadas em um estudo de campo desenvolvido na região de Tefé, no Médio Solimões. Foram estudadas 12 comunidades localizadas em ecossistemas de várzea e terra firme, das quais 6 adotaram um modelo de manejo de recursos naturais, com enfoque em manejo de lagos e as outras 6 nunca participaram de processos de manejo. As percepções dos comunitários em relação aos impactos do manejo sobre o ecossistema também foram analisadas. A percepção de benefício em relação ao manejo foi fundamental para o incentivo á conservação. $\mathrm{O}$ modelo de manejo adotado foi mais adequado às comunidades de várzea do que para as comunidades de terra firme, em função das próprias características dos ecossistemas.de Macapá e a várzea da Amazônia peruana.

\section{Palavras-Chave}

Manejo de recursos naturais, Amazônia, pesca, caça, agricultura, exploração madeireira, coleta produtos não madeireiros.

\section{Abstract}

The theoretical bases of conservationism and preservation are discussed in this research, based on a field study carried out in the region of Tefé, the Middle Solimões. Twelve communities located in "Varzea" and "Terra Firme" ecosystems were studied, of which six communities have adopted a model of natural resource management, focusing on management of lakes and the other six have never participated in processes of management. The data of "Terra Firme" communities with and without management, not different from "Varzea" communities without management, in relation to perceptions of impact. The use of managed resources allowed greater control of them by the users. The model of management adopted was more appropriate to the communities in "Varzea" than in the communities of "Terra Firme", according to the own characteristics of ecosystems.

\section{Keywords}

Management of natural resources, Amazon, fishing, hunting, farming, logging, collecting non-timber products. 


\section{INTRODUÇÃO}

Há vários anos que a natureza vem levando desvantagens no processo de desenvolvimento regional da Amazônia, em prol de um crescimento social e econômico, muitas vezes mal sucedido. Desde a sua descoberta, a região amazônica vem despertando o interesse humano através da riqueza de seus recursos naturais (Anderson, 1990; Becker, 2001). A dificuldade de acesso e a presença de alternativas econômicas em outras regiões do país fizeram com que a Amazônia brasileira permanecesse inexplorada por um longo período de tempo. Mesmo após uma colonização desenfreada que assolou a região, principalmente após a década de 70, com o processo de abertura de estradas na região, ainda hoje, este complexo bioma guarda em si riquezas incalculáveis.

Nos últimos 40 anos, a colonização da Amazônia tem sido marcada pela degradação de seus recursos naturais, principalmente com a derrubada de suas áreas florestadas e empobrecimento de seus solos. Por outro lado, recentemente, esta mesma região vem experimentando novas alternativas de desenvolvimento e novas estratégias de uso de recursos, que tem como proposta permitir uma exploração sustentável dos recursos naturais da região, atrelada ao desenvolvimento social e econômico das populações nela residentes (Cunha \& Almeida, 2001). Vários grupos da sociedade civil, do governo e da iniciativa privada têm contribuído para o avanço destas experiências (Campos \& Nepstad, 2006; Lima et al., 2006).

Este trabalho analisa a atuação de comunidades rurais, que apesar de potenciais degradadores do meio ambiente, podem se tornar fortes aliados no processo de conservação da Amazônia. Estes atores sociais, em sua maioria, dependem diretamente dos recursos naturais para sua sobrevivência e sua ligação com recursos naturais se caracteriza por relações que vão além da dependência econômica, incluindo também os valores de subsistência, os valores culturais e relações socioambientais.

Nos últimos 25 anos, várias comunidades têm se envolvido em iniciativas de manejo na Amazônia brasileira, em resposta ao aumento da pressão sobre os recursos naturais de que dependem (McGrath et al., 1998, McGrath et al., 2007; Queiroz \& Crampton, 1999; Castro \& McGrath, 2001; Castro et al., 2002; Cunha, 2002; Benatti et al., 2003; Almeida et al., 2009). Na região do Médio Solimões, o aumento da pressão sobre os estoques pesqueiros levou dezenas de comunidades ribeirinhas a se envolverem em iniciativas de preservação de lagos e de seus estoques pesqueiros. A intensificação da pesca nesta região se deu principalmente a partir das décadas de 70 e 80, em função da introdução do nylon na produção de redes, aumentando a produtividade da atividade de pesca; da introdução do gelo nas 
Impactos ecológicos do manejo comunitário de recursos naturais em comunidades ribeirinhas de várzea e terra firme na região de Tefé, AM

pescarias, permitindo a conservação do peixe por mais tempo e do aumento da demanda pelo pescado nos principais centros urbanos da região, especialmente Manaus, com a criação de seu pólo industrial e da zona franca (Barthem, 1987; Barthem et al., 1997, 1999).

Este trabalho de pesquisa analisou uma experiência de dezoito anos de manejo comunitário de lagos, realizado por 26 comunidades rurais localizadas na região do Médio Solimões. Estas comunidades criaram uma Associação chamada "Grupo de Preservação e Desenvolvimento" (GPD) que com o incentivo da Igreja Católica da região, organizava e disseminava o modelo de manejo adotado.

\section{O MODELO DE MANEJO DAS COMUNIDADES RURAIS DO MÉDIO SOLIMÕES}

O aumento da pressão sobre o pescado na região amazônica acirrou os conflitos entre pescadores comerciais e pescadores artesanais (dedicados à atividade da pesca para subsistência e/ou comercialização), em disputa pelos estoques pesqueiros dos lagos de várzea e de terra firme no Médio Solimões (Faulhaber, 1987; Barthem, 1999). Nesta mesma época, a Igreja Católica que já atuava nesta região na formação de comunidades de base, passou a incentivar ações coletivas que buscassem novas formas de regulação do acesso e uso dos recursos pesqueiros dos lagos tradicionalmente utilizados para pesca, pelos ribeirinhos. Em meados da década de 80, sob a influência de representantes da Igreja Católica, algumas comunidades localizadas próximas à cidade de Tefé criaram um modelo de manejo de lagos embasado na preservação do recurso pesqueiro para a subsistência das comunidades locais.

O modelo de manejo adotado pelas comunidades da região do Médio Solimões se caracterizava pela definição de lagos e igarapés da região em três categorias: lagos de procriação, onde a pesca tanto para comercialização quanto para subsistência era proibida; lagos de manutenção, onde somente a pesca para subsistência das famílias da comunidade era permitida e lagos livres, onde a pesca não sofria restrições comunitárias. Apesar de adotarem arranjos institucionais e organizacionais sem grandes variações (Cunha 2002), as comunidades envolvidas no movimento de reserva de lagos alcançaram resultados diferentes em termos de conservação dos estoques pesqueiros, ao longo dos 18 anos de manejo resgatados neste estudo.

O estudo foi desenvolvido em 12 comunidades rurais, sendo 6 comunidades envolvidas no processo de manejo de lagos ( 3 localizadas no ecossistema de várzea e 3 localizadas no ecossistema de terra firme) e em 6 comunidades que nunca 
instituíram regras locais de acesso aos lagos e de uso de seus estoques pesqueiros (3 localizadas no ecossistema de várzea e 3 localizadas no ecossistema de terra firme). As comunidades estudadas se encontravam distribuídas em três municípios próximos à cidade de Tefé, próximo à foz do Rio Solimões, à $600 \mathrm{Km}$ da cidade de Manaus, estado do Amazonas, Brasil (Figura 1).
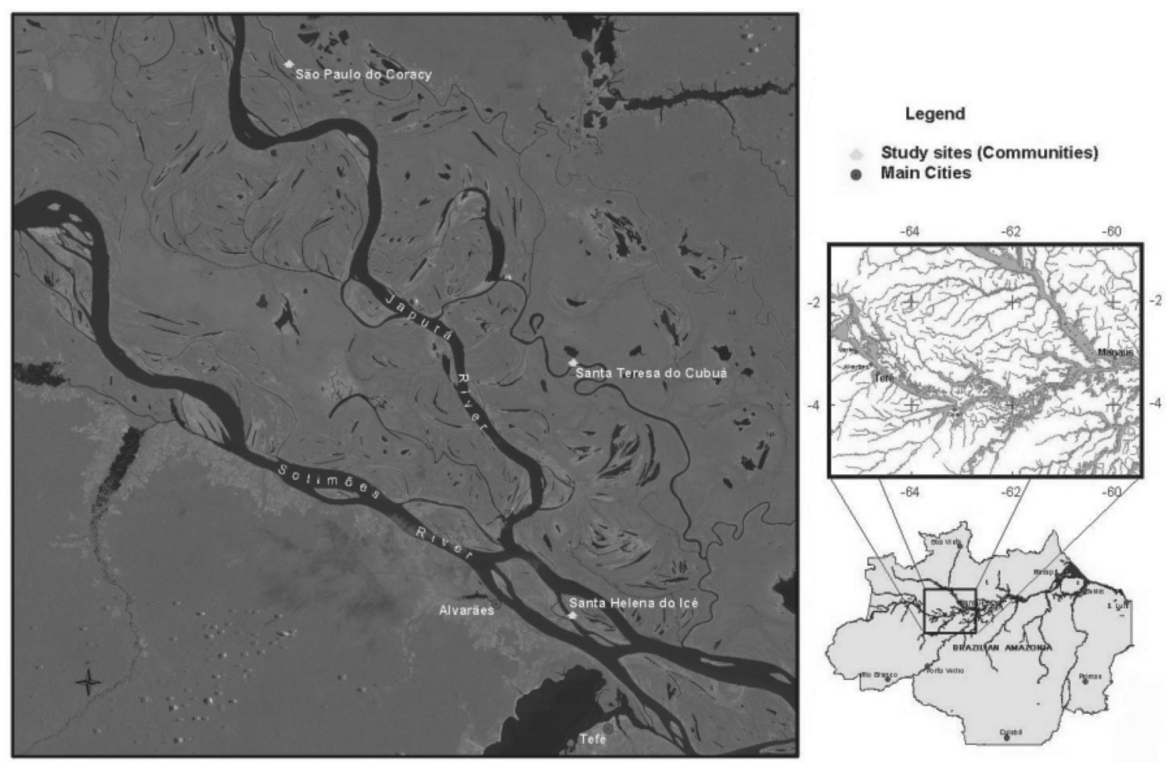

Figura 1 - Localização da Região de Tefé no Médio Solimões, Estado do Amazonas, Brasil.

\section{O ECOSSISTEMA DE VÁRZEA NO MÉDIO SOLIMÕES}

A várzea Amazônica pode ser definida como sendo as áreas em ambos os lados do canal principal, periodicamente inundados, pelo transbordamento das águas ricas em sedimentos do Rio Amazonas (McGrath et al, 1993). Estas planícies inundáveis do Rio Amazonas ocupam 2\% do total da área da Bacia Amazônica, mas desempenham um papel bem maior do que sua pequena área indica (Padoch et al, 1999). Estas áreas inundáveis são bastante diferentes do resto da Bacia. Geralmente, com alta produtividade biológica, a várzea amazônica inclui uma grande diversidade de ambientes e ecossistemas compreendidos em pequenas áreas. Muitos habitats das planícies inundáveis são cruciais para a reprodução de inúmeras espécies da fauna. São, ainda, lugar de moradia de algumas populações endêmicas.

Os Rios Solimões e Japurá são os principais rios que banham as planícies inundáveis da região de várzea do Médio Solimões, onde este estudo foi realizado. Estas planícies possuem um mosaico de corpos d'água, que em conexão com os 
Impactos ecológicos do manejo comunitário de recursos naturais em comunidades ribeirinhas de várzea e terra firme na região de Tefé, AM

rios, se ramificam, formando lagos e igarapés no interior das várzeas da região (Henderson, 1999). Pode-se destacar aí três tipos de habitats diferentes: as restingas altas e baixas e os chavascais. As restingas altas correspondem aos terrenos mais altos da várzea, que estão sujeitos à alagação anual por 2 a 4 meses. Estas áreas são estruturalmente parecidas com as florestas de terra firme, mas a composição de espécies é bastante diferente. Já as restingas baixas, com sub-bosque mais limpo e melhor visibilidade, podem ser consideradas como a transição entre as áreas florestais da várzea para os chavascais. As restingas baixas permanecem inundadas durante 4 a 6 meses por ano. Os chavascais representam a maior porção da várzea nesta região. Este tipo fisionômico consiste em áreas bastante extensas de vegetação baixa, arbustiva, pantanosa e quase impossível de transpor durante a seca (Ayres, 1995). O chavascal é inundado durante cerca de 6 a 8 meses por ano. Freqüentemente, encontramos restingas intercaladas com chavascais, longe das margens dos rios. Isto se deve à mudança nas rotas dos rios. A região de mata, seja no chavascal ou na restinga, alagada na época da cheia, ganha a denominação de Igapó.

Os lagos são a principal unidade da paisagem da várzea e podem ter até centenas de quilômetros quadrados. No período da seca são bastante rasos e raramente excedem a quatro metros de profundidade. Os lagos têm uma função importante na produtividade do ecossistema aquático (McGrath et al, 1993). A entrada anual de águas ricas em nutrientes durante a estação das cheias contribui para a produção de macrófitas e fitoplânctons. A vegetação flutuante, que pode cobrir a maior parte da superfície do lago, serve como a principal área de alimentação e de criação para vertebrados e invertebrados aquáticos. As florestas sazonalmente inundadas nas terras altas que margeiam os lagos, que incluem os chavascais e parte das restingas, constituem outra importante área de alimentação, e muitas espécies de peixes dependem dos frutos e sementes dispersados durante a estação inundada nestas áreas (McGrath et al, 1993).

\section{O ECOSSISTEMA DE TERRA FIRME}

As florestas de terra firme ocupam cerca de 80 a 90\% da área total da Amazônia. Dentro da classificação de matas de terra firme, Ayres (1995) descreveu vários tipos fisionômicos de florestas na Amazônia, definidos segundo Pires (1973) e Prance (1978). Entre eles estão a mata primária alta e a mata de cipó que são os dois tipos mais comuns encontrados na região de Tefé. Estas florestas não sofrem inundações como na várzea, mesmo no período de intensa pluviosidade.

A mata primária alta é o tipo mais comum de vegetação da Amazônia, sendo caracterizada por elevada biomassa e alta biodiversidade (Ayres, 1995). A 
composição deste tipo de floresta é extremamente variável. Entretanto, em vários locais, as plantas da família Leguminosae detêm o maior número de espécies, seguidas por Annonaceae, Moraceae e Burseraceae.

As florestas de terra firme localizam-se geralmente em terrenos ondulados, com baixas altitudes, raramente excedendo 250 metros acima do nível do mar. Estas florestas possuem também as árvores mais altas, algumas atingindo cerca de $50 \mathrm{~m}$ de altura, como é o caso do angelim-pedra (Diniza excelsa). Os solos são variáveis: vão desde latossolos pobres à terra roxa, encontrada em algumas regiões do sul da Amazônia. Mas predomina a composição de latossolos amarelos e vermelhos, que representam 70\% de toda terra firme da Amazônia.

Os lagos também ocorrem nos ecossistemas de terra firme. Eles se diferem dos lagos da várzea por serem permanentes. Geralmente são lagos grandes, abastecidos por nascentes. Na época da cheia, estes lagos sofrem influência dos rios e suas águas se tornam mais turvas pelos sedimentos dos Rios Solimões e Japurá. Na seca, suas águas permanecem escuras e cristalinas, caracterizando a pobreza de sedimentos da água, advindo de suas nascentes, em relação aos rios. A diferença na composição das águas influencia na composição de espécies de peixes, entre lagos de terra firme, rios e lagos de várzea.

\section{MÉTODOS}

O estudo em campo teve duração de 2 anos. Inicialmente, foi feito o contato com as lideranças comunitárias e associações locais ligadas ao processo de manejo de lagos realizado na região, como o Grupo de Preservação e Desenvolvimento (GPD) e a Prélasia de Tefé. Através destas lideranças foi possível visitar as comunidades e dar início ao trabalho de esclarecimento e consulta sobre o interesse de cada uma delas em participar deste projeto de pesquisa. Foram escolhidas doze comunidades descritas na Tabela I.

A análise deste trabalho se concentrou na comparação entre seis comunidades que adotaram o modelo de manejo de lagos e seis comunidades que não adotaram tal iniciativa de manejo, todas elas inseridas no mesmo contexto sócio-econômico. Foram estabelecidas, duas categorias de variáveis independentes para efeito de comparação: a diferença de ecossistemas (várzea e terra firme) e a participação ou não no modelo de manejo comunitário de recursos naturais. Na comparação foram analisados os tipos e estratégias de uso dos diferentes recursos naturais e as percepções dos ribeirinhos sobre a situação dos recursos naturais na área. Apesar do manejo adotado por estas comunidades dar ênfase aos recursos pesqueiros, buscou-se analisar como o processo e a organização para adoção do modelo de manejo influenciou nas estratégias gerais de uso de recursos naturais. 
Impactos ecológicos do manejo comunitário de recursos naturais em comunidades ribeirinhas de várzea e terra firme na região de Tefé, AM

Tabela I - Relação das comunidades estudadas na região do Médio Solimões.

\begin{tabular}{l|c|c}
\hline \multicolumn{1}{c|}{ Comunidades } & Ecossistema & Modelo de Manejo \\
\hline Santa Teresa do Cubuá & Várzea & Com manejo \\
\hline Santa Helena do Ice & Várzea & Com manejo \\
\hline São Paulo do Coracy & Várzea & Com manejo \\
\hline Santa Luzia do Catuiri & Terra Firme & Com manejo \\
\hline Boa Esperança do Amanã & Terra Firme & Com manejo \\
\hline Bela Conquista & Terra Firme & Com manejo \\
\hline Santa Rosa & Várzea & Sem manejo \\
\hline São Joaquim & Várzea & Sem manejo \\
\hline Ebenézer & Várzea & Sem manejo \\
\hline Itapiranema & Terra Firme & Sem manejo \\
\hline Bom Jesus do Baré & Terra Firme & Sem manejo \\
\hline Juruamã & Terra Firme & Sem manejo
\end{tabular}

Nas doze comunidades estudadas foram aplicados 132 questionários, mantendo um percentual superior a $40 \%$ de unidades domésticas (UDs) entrevistadas em cada uma das comunidades. Com estes questionários, foi possível o levantamento de dados quantitativos e qualitativos relacionados ao uso atual e passado dos recursos naturais; levantamento das atividades econômicas atuais e passadas (antes do início do processo de manejo); e a percepção dos entrevistados sobre a situação atual dos recursos naturais em relação ao passado (antes do início do processo de manejo). Além dos questionários foram aplicados outros métodos de coleta de dados participativos como mapas de uso da terra, tendo como base as imagens de satélites (Landsat, 1998) de cada comunidade.

Também foram realizadas entrevistas individuais e participativas para levantamento de dados históricos de uso dos recursos e sobre as características de colonização de cada comunidade. Baseado nos dados coletados, realizou-se uma análise temporal sobre as mudanças sofridas pelo modelo de manejo nas seis comunidades participantes do manejo, levando em consideração as características sócio econômicas e ambientais de cada uma, permitindo visualizar pontos positivos e negativos ao longo do processo de manejo.

Foram aplicados testes de Análise de Cluster, baseadas em distância euclidiana, na tentativa de visualizar padrões de similaridade de riqueza de espécies de peixes explorados e atividades econômicas desenvolvidas, entre as doze comunidades estudadas. Foi aplicado o "Teste G” de estatística não paramétrica (Ayres, et al, 2000), para verificar se as diferenças entre as categorias de registros respondidas eram significativas entre as comunidades com e sem manejo e comunidades de várzea e terra firme. Os dados foram analisados na forma de porcentagem de registros para cada comunidade separadamente, já que o número de unidades domésticas entrevistadas é diferente de uma comunidade para outra. 


\section{RESULTADOS}

\section{Estratégias locais de uso dos recursos naturais - Comunidades de Várzea}

A diversidade de ambientes da várzea tem proporcionado o desenvolvimento de uma grande variedade de padrões de uso da terra. Os solos aluviais renovados todo ano são bastante férteis. Entretanto, a mesma inundação que torna a agricultura atraente, também provoca dificuldades na utilização de métodos agrícolas modernos. A facilidade de acesso e a alta densidade populacional aumentam o risco de superexploração dos recursos biológicos e físicos neste ecossistema.

Além da agricultura e da pesca que foram as atividades econômicas predominantemente registradas, as atividades de caça, exploração madeireira, coleta de produtos vegetais não madeireiros e criação de animais também foram registradas pelas Unidades Domésticas (UDs) entrevistadas nas comunidades de várzea. Nas comunidades que realizam manejo, a agricultura foi a atividade comercial predominante tanto no período do estudo (para 74,2\% das UDs entrevistadas), quanto no passado (para 58,5\% das UDs entrevistadas), antes do início da disseminação do modelo de manejo na região de Tefé. Também nestas comunidades, a agricultura foi considerada a atividade que trazia maior renda para 82,7\% das UDs, sendo também onde a maior parte das famílias (87,8\% dos entrevistados) gastavam seu tempo destinado à atividades econômicas. Apesar da pesca também aparecer como atividade comercial tanto no período do estudo (para 17,1\% das UDs entrevistadas), quanto no passado (para 34,2\% das UDs entrevistadas), esta atividade representou o fator de maior retorno monetário apenas para 13,7\% das UDs entrevistadas nas comunidades de várzea com manejo.

Nas comunidades de várzea sem manejo, verificou-se que a pesca e a agricultura tinha mesmo nível de importância comercial no período do estudo (para 59\% das famílias entrevistadas), e no passado esta importância também era bem próxima, sendo que a pesca era desenvolvida de forma comercial por $68,2 \%$ das famílias entrevistadas e a agricultura, por 63,6\% das famílias entrevistadas. Mas neste caso, a pesca representou a atividade de maior retorno monetário para 57,8\% das UDs, seguido de 36,8\% dos registros para a agricultura, entretanto 73,7\% dos entrevistados passam mais tempo na atividade agrícola do que na pesca.

A Tabela II apresenta as espécies de peixes mais exploradas, citadas pelas comunidades de várzea estudadas. Entre elas, 20 espécies eram comercializadas tanto no mercado local, quanto na cidade de Tefé. Apenas 9 espécies eram comercializadas nos dois grupos de comunidades (com e sem manejo), 7 somente eram comercializadas em comunidades sem manejo e 3 espécies somente 
comercializadas em comunidades com manejo, entre elas as duas espécies de maior valor comercial da região, o pirarucu (Arapaima gigas) e o tambaqui (Colossoma macropomum).

Tabela II - Espécies de peixes exploradas pelas comunidades de várzea estudadas, com e sem manejo.

\begin{tabular}{|c|c|c|c|c|}
\hline \multirow{2}{*}{$\begin{array}{l}\text { Nome } \\
\text { Local }\end{array}$} & \multirow[b]{2}{*}{ Gênero/Espécie } & \multirow{2}{*}{$\begin{array}{c}\text { Tipo de } \\
\text { uso* }^{*}\end{array}$} & \multicolumn{2}{|c|}{ Tipo de Comunidade } \\
\hline & & & $\begin{array}{c}\text { com } \\
\text { manejo }\end{array}$ & $\begin{array}{c}\text { sem } \\
\text { manejo }\end{array}$ \\
\hline Aracú & Leporinus sp. & Subs. & $\mathrm{X}$ & \\
\hline Aruanã & Osteoglossum bicirrhosum & Subs./Com. & $\mathrm{X}$ & $\mathrm{X}$ \\
\hline Bodó & Hypostomus sp. & Subs./Com. & $\mathrm{X}$ & $\mathrm{X}$ \\
\hline Cará & Cichlasoma facetum & Subs./Com. & $\mathrm{X}$ & $\mathrm{X}$ \\
\hline Cara-açú & Astronotus ocellatus & Subs. & $\mathrm{X}$ & $\mathrm{X}$ \\
\hline Cascudo & Hemipsilichthus gobio & Subs. & $\mathrm{X}$ & \\
\hline Curimatá & Prochilodus nigricans & Subs./Com. & $\mathrm{X}$ & \\
\hline Dourada & Brachyplatystoma flavicans & Subs./Com. & $\mathrm{X}$ & $\mathrm{X}$ \\
\hline Filhote & Brachyplatystomafilamentosum & Subs./Com. & & $\mathrm{X}$ \\
\hline Jandiá & Rhamdia sebae & Subs./Com. & & $\mathrm{X}$ \\
\hline Jaraqui & Semaprochilodus sp. & Subs. & $\mathrm{X}$ & \\
\hline Jaú & Paulicea lutkeni & Subs./Com. & & $\mathrm{X}$ \\
\hline Matrinchã & Brycon sp. & Subs. & $\mathrm{X}$ & $\mathrm{X}$ \\
\hline Pacu & Metynnis sp. & Subs./Com. & $X$ & $X$ \\
\hline Piraíba & Brachyplatystoma sp. & Subs./Com. & & $\mathrm{X}$ \\
\hline Piranha & Serrasalmus sp. & Subs./Com. & $\mathrm{X}$ & $\mathrm{X}$ \\
\hline Pirarara & Phractocephalushemiliopterus & Subs. & $\mathrm{X}$ & \\
\hline Pirapitinga & Piaractus brachypomus & Subs./Com. & & $\mathrm{X}$ \\
\hline Pirarucu & Arapaima gigas & Subs./Com. & $\mathrm{X}$ & \\
\hline Pirauaca & Sorubimichthys planiceps & Subs./Com. & $\mathrm{X}$ & $\mathrm{X}$ \\
\hline Sardinha & Triportheus sp. & Subs./Com. & & $\mathrm{X}$ \\
\hline Surubim & Pseudoplatystomafasciatum & Subs./Com. & & $\mathrm{X}$ \\
\hline Tambaqui & Colossoma macropomum & Subs./Com. & $\mathrm{X}$ & \\
\hline Traira & Hoplias malabaricus & Subs./Com. & $\mathrm{X}$ & $\mathrm{X}$ \\
\hline Tucunaré & Cichla sp. & Subs./Com. & $\mathrm{X}$ & $\mathrm{X}$ \\
\hline
\end{tabular}

* Tipo de uso: subsistência e/ou comercial

As estratégias agrícolas utilizadas nas comunidades de várzea com e sem manejo são as mesmas, sendo a agricultura de corte e queima a estratégia predominante e tendo como base de cultivo, a banana e a mandioca, para produção artesanal da farinha. O cultivo é feito principalmente no final do período chuvoso, permitindo apenas uma safra por ano.

A média de tempo de pousio da área de agricultura para as comunidades localizadas no ecossistema de várzea foi de 2 anos ( \pm 0,57 anos). A média de idade das capoeiras mais antigas foi de 5,8 anos ( \pm 1,5 anos) nas comunidades com 
manejo e de 4,5 anos ( $\pm 2,0$ anos) nas as comunidades sem manejo. O tamanho da safra de farinha produzida em um ano, não diferiu muito entre as comunidades com e sem manejo (média $=553,8 \mathrm{~kg} / \mathrm{safra} \pm 430,2$ e $582,1 \mathrm{~kg} / \mathrm{safra} \pm 210,3$, respectivamente). Entretanto, a safra de banana em um ano nas comunidades sem manejo (138,40 cachos/safra) representou mais do que o dobro da safra das comunidades com manejo (55 cachos/safra) no mesmo ano.

A exploração de recursos madeireiros não vinha sendo uma atividade comercial tão importante quanto foi em épocas passadas, principalmente para as comunidades com manejo. Nestas comunidades, a introdução do manejo de lagos acabou por incentivar regras relacionadas a outros tipos de recursos, como a não comercialização de espécies madeireiras. Nas comunidades sem manejo, esta atividade também passou a ter menor importância comercial, por dois motivos: a diminuição do recurso em suas áreas, provocado pela pressão de exploração e o aumento da fiscalização pelo IBAMA sobre esta atividade na região. A Tabela III apresenta as principais espécies madeireiras exploradas pelas comunidades de várzea. A maioria das espécies madeireiras era utilizada para a construção de casas e confecção de embarcações (canoas). Com exceção da muiratinga (Maquira sp.), todas as outras espécies somente eram comercializadas nas comunidades sem manejo. Nestas, a comercialização era desenvolvida por alguns moradores que vendiam a madeira em tora para madeireiros da região, a preços baixos, como é o caso do açacu (Hura creptans), vendido à U\$5,0/ $\mathrm{m}^{3} /$ tora.

Tabela III - Principais espécies madeireiras exploradas nas comunidades de várzea, com e sem manejo.

\begin{tabular}{lllcc}
\hline \multirow{2}{*}{ Nome Local } & \multicolumn{1}{c}{ Gênero/Espécie } & \multicolumn{1}{c}{$\begin{array}{c}\text { Tipo de } \\
\text { uso* }\end{array}$} & & \multicolumn{2}{c}{ Tipo de Comunidade } \\
\cline { 5 - 5 } & & & com manejo & com manejo \\
\hline Acapu & Vouacapoua pallidior & Subs. & & $\mathrm{X}$ \\
Açacu & Hura crepitans & Subs./Com. & & $\mathrm{X}$ \\
Cupiuba & Goupia glabra & Subs. & & $\mathrm{X}$ \\
Jenipapo & Genipa americana & Subs. & & $\mathrm{X}$ \\
Itaúba & Mezilaurus itauba & Subs. & & $\mathrm{X}$ \\
Jitó & Guarea subssessiliflora & Subs. & $\mathrm{X}$ & $\mathrm{X}$ \\
Jacareúba & Calophyllumbrasiliense & Subs. & $\mathrm{X}$ & $\mathrm{X}$ \\
Louro inamuí & Ocotea cymbarum & Subs. & $\mathrm{X}$ & $\mathrm{X}$ \\
Louro abacate & Ocotea tabacifolia & Subs. & $\mathrm{X}$ & $\mathrm{X}$ \\
Macaca & Platymiscium duckei & Subs./Com. & $\mathrm{X}$ & $\mathrm{X}$ \\
Muiratinga & Maquira coriacea & Subs./Com. & $\mathrm{X}$ & $\mathrm{X}$ \\
Mulateiro & Capirona decorticans & Subs. & & $\mathrm{X}$ \\
Piranheira & Piranhea trifoliata & Subs. & & $\mathrm{X}$ \\
Paricarana & Pithecellobiumcorymbosum & Subs./Com. & & $\mathrm{X}$ \\
Samaumeira & Ceiba pentandra & Subs. & & $\mathrm{X}$ \\
\hline
\end{tabular}

* Tipo de uso: subsistência e/ou comercial 
A criação de animais e a coleta de produtos não madeireiros da floresta eram consideradas atividades comerciais complementares à pesca e à agricultura. Em duas das comunidades sem manejo: Santa Rosa e Ebenézer, a criação de gado servia como uma espécie de poupança para os comunitários, que vendiam o boi numa situação de emergência. A criação de gado era realizada em pequena escala, já que a várzea desta região não se caracteriza pela presença de campos, como no baixo amazonas. $\mathrm{Na}$ época da cheia, os animais ficam confinados às terras mais altas. Já a exploração de produtos não madeireiros para comercialização se concentrava na coleta de frutos do açaí (Euterpe oleracea) e do cacau (Theobroma cacao). A safra por família tanto da coleta do açaí (com manejo: 1.050kg \pm 840; sem manejo: $1.110 \mathrm{~kg} \pm 1.255)$ quanto do cacau não diferiu muito entre comunidades com e sem manejo. Entretanto, nas comunidades de várzea com manejo, existiam mais famílias desenvolvendo esta atividade do que nas comunidades sem manejo.

A caça, apesar de ser uma atividade importante, não desempenha papel econômico fundamental para estas comunidades. Esta era uma atividade desenvolvida principalmente no período da cheia, quando os animais ficam ilhados, facilitando a captura, e coincidindo com a época de maior escassez de peixe. A Tabela IV apresenta os principais animais de caça explorados nas comunidades de várzea com e sem manejo.

Tabela IV - Principais animais de caça explorados nas comunidades de várzea, com e sem manejo.

\begin{tabular}{|c|c|c|c|c|c|}
\hline \multirow{2}{*}{$\begin{array}{l}\text { Nome } \\
\text { Local }\end{array}$} & \multirow[t]{2}{*}{ Classe } & \multirow[b]{2}{*}{ Gênero/Espécie } & \multirow{2}{*}{$\begin{array}{c}\text { Tipo de } \\
\text { uso* }^{*}\end{array}$} & \multicolumn{2}{|c|}{ Tipo de Comunidade } \\
\hline & & & & $\begin{array}{c}\text { com } \\
\text { manejo }\end{array}$ & $\begin{array}{c}\text { sem } \\
\text { manejo }\end{array}$ \\
\hline Tatu & Mammalia & Dasypus sp. & Subs. & $\mathrm{X}$ & \\
\hline Guariba & Mammalia & Alouatta seniculus & Subs. & $\mathrm{X}$ & $\mathrm{X}$ \\
\hline Mucura & Mammalia & Didelphis sp. & Subs. & $\mathrm{X}$ & \\
\hline Queixada & Mammalia & Tayassu pecari & Subs./Com. & $\mathrm{X}$ & $\mathrm{X}$ \\
\hline Anta & Mammalia & Tapirus terrestris & Subs./Com. & $\mathrm{X}$ & \\
\hline Veado & Mammalia & Mazama spp. & Subs./Com. & $\mathrm{X}$ & $\mathrm{X}$ \\
\hline Cutia & Mammalia & Dasyprocta cristata & Subs./Com. & $\mathrm{X}$ & $\mathrm{X}$ \\
\hline Paca & Mammalia & Cuniculus paca & Subs./Com. & $\mathrm{X}$ & $\mathrm{X}$ \\
\hline Pato & Ave & Cairina moschata & Subs. & $\mathrm{X}$ & $\mathrm{X}$ \\
\hline Mutum & Ave & Mitu sp. & Subs. & $\mathrm{X}$ & $\mathrm{X}$ \\
\hline Marreco & Ave & Dendrocygnaautumalis & Subs. & & $\mathrm{X}$ \\
\hline Jabuti & Reptilia & Geochelonedenticulata & Subs. & $\mathrm{X}$ & $\mathrm{X}$ \\
\hline
\end{tabular}

* Tipo de uso: subsistência e/ou comercial 


\section{ESTRATÉGIAS LOCAIS DE USO DOS RECURSOS NATURAIS - COMUNIDADES DE TERRA FIRME}

Os pequenos produtores têm grande participação no processo de mudança na paisagem dos ecossistemas de terra firme no Médio Solimões. Embora mais sutil do que na várzea, a diversificação de atividades econômicas tem sido uma estratégia de sobrevivência comum entre os moradores destas áreas. Nas comunidades de terra firme estudadas na região de Tefé, a diferença entre comunidades com e sem manejo de lagos, com relação à dinâmica de uso dos recursos não é muito aparente, como veremos a seguir.

Quando questionados sobre quais as atividades econômicas desenvolvidas atualmente, a agricultura e a pesca também foram as mais registradas pelas unidades domésticas entrevistadas nas comunidades de terra firme. Entretanto, a atividade de pesca somente era desenvolvida para comercialização por 4,3\% das famílias entrevistadas nas comunidades sem manejo, sendo que nas comunidades com manejo esta atividade somente era desenvolvida para subsistência. Já a agricultura era desenvolvida para comercialização por todas as famílias entrevistadas nos dois tipos de comunidades de terra firme (com e sem manejo). Também eram na atividade agrícola que as famílias gastam a maior parte do tempo de trabalho e ganham mais dinheiro, sendo que esta atividade traz mais renda para 97,4\% dos entrevistados nas comunidades com manejo e 89,4\% para as famílias entrevistadas nas comunidades sem manejo. No passado, a atividade agrícola tinha praticamente a mesma importância comercial do presente, tanto para comunidades com manejo quanto para comunidades sem manejo, enquanto a pesca teve um declínio como atividade comercial para as famílias entrevistadas, principalmente entre as comunidades sem manejo.

Nas comunidades de terra firme, o fator limitante para a queda na atividade de pesca, como fonte de renda direta, foi a escassez do recurso. É importante salientar que as comunidades de terra firme se localizam às margens de lagos de terra firme, caracterizados por serem grandes e permanentes. Nestes lagos, a pressão pesqueira tem sido bastante alta, enquanto que o controle por parte das comunidades locais é bem mais difícil. O manejo pesqueiro, nestas comunidades, concentra-se no controle dos Igarapés temporários, que são espécie de braços de lagos formados na época da seca, onde os peixes ficam represados, facilitando a pesca. Entretanto, a alta pressão sobre o recurso durante todo o ano no restante do lago resulta na diminuição do estoque pesqueiro, inclusive nos igarapés.

A Tabela $\mathrm{V}$ apresenta as espécies de peixes mais exploradas, citadas pelas comunidades de terra firme estudadas. Entre elas, apenas 2 espécies eram 
comercializadas tanto no mercado local, quanto na cidade de Tefé, somente por comunidades sem manejo. Não houve registro de ocorrência de pesca das duas espécies de maior valor comercial da região, o pirarucu (Arapaima gigas) e o tambaqui (Colossoma macropomum) nas comunidades sem manejo, nem para consumo nem para comercialização.

Tabela V - Espécies de peixes exploradas pelas comunidades de Terra Firme estudadas, com e sem manejo.

\begin{tabular}{|c|c|c|c|c|}
\hline \multirow{2}{*}{$\begin{array}{l}\text { Nome } \\
\text { Local }\end{array}$} & \multirow[b]{2}{*}{ Gênero/Espécie } & \multirow{2}{*}{$\begin{array}{c}\text { Tipo de } \\
\text { uso } *\end{array}$} & \multicolumn{2}{|c|}{ Tipo de Comunidade } \\
\hline & & & $\begin{array}{c}\text { com } \\
\text { manejo }\end{array}$ & $\begin{array}{c}\text { sem } \\
\text { manejo }\end{array}$ \\
\hline Acará & Aeguidens sp. & Subs. & & $\mathrm{X}$ \\
\hline Aracu & Leporinus sp. & Subs. & $\mathrm{X}$ & $\mathrm{X}$ \\
\hline Aruanã & Osteoglossum bicirrhosum & Subs. & $\mathrm{X}$ & $\mathrm{X}$ \\
\hline Bacu & Lithodoras dorsalis & Subs. & $X$ & \\
\hline Bodó & Hypostomus sp. & Subs. & & $\mathrm{X}$ \\
\hline Branquinha & Curimata sp. & Subs. & $\mathrm{X}$ & \\
\hline Cará & Cichlasoma facetum & Subs. & $\mathrm{X}$ & $\mathrm{X}$ \\
\hline Carauaçu & Astronotus ocellatus & Subs. & $X$ & $\mathrm{X}$ \\
\hline Cubiu & Anodus melanopogum & Subs. & $X$ & \\
\hline Cuiucuiu & Pseudodoras niger & Subs. & $\mathrm{X}$ & \\
\hline Curimatã & Prochilodus nigricans & Subs. & $X$ & $X$ \\
\hline Jacundá & Crenicichla sp. & Subs. & & $\mathrm{X}$ \\
\hline Jaraqui & Semaprochilodus sp. & Subs. & $\mathrm{X}$ & \\
\hline Jeju & Hoploerythrinus unitaeniatus & Subs. & & $\mathrm{X}$ \\
\hline Mandi & Pimelodus sp. & Subs. & & $\mathrm{X}$ \\
\hline Mapará & Hypophthalmus sp. & Subs. & $X$ & \\
\hline Matrincha & Brycon sp. & Subs. & $\mathrm{X}$ & \\
\hline Orana & Hemiodopsis sp. & Subs. & $X$ & \\
\hline Pacu & Metynnis sp. & Subs. & $X$ & $\mathrm{X}$ \\
\hline Peixe cachorro & Cynodon gibbus & Subs. & $\mathrm{X}$ & \\
\hline Pescada & Pachypops sp. & Subs. & & $X$ \\
\hline Piau & Leporinus frederici & Subs. & $\mathrm{X}$ & $\mathrm{X}$ \\
\hline Piranha & Serrasalmus sp. & Subs. & $\mathrm{X}$ & \\
\hline Pirapitinga & Piaractus brachypomus & Subs. & $\mathrm{X}$ & $X$ \\
\hline Pirarucu & Arapaima gigas & Subs. & $X$ & \\
\hline Rabeca & Megalodoras irwini & Subs. & $\mathrm{X}$ & $\mathrm{X}$ \\
\hline Sardinha & Triportheus sp. & Subs. & $X$ & \\
\hline Sardinhao & Pellona sp. & Subs. & $X$ & $\mathrm{X}$ \\
\hline Surubin & Pseudoplatystoma fasciatum & Subs./Com. & & $\mathrm{X}$ \\
\hline Tambaqui & Colossoma macropomum & Subs. & $X$ & \\
\hline Traira & Hoplias sp. & Subs. & $X$ & $\mathrm{X}$ \\
\hline Tambaqui & Colossoma macropomum & Subs. & $\mathrm{X}$ & \\
\hline Tucunaré & Cichla monoculus & Subs./Com. & $X$ & $X$ \\
\hline
\end{tabular}

* Tipo de uso: subsistência ou comercial 
A base do cultivo agrícola comercial das comunidades de terra firme se concentra na banana e na mandioca, para a fabricação artesanal da farinha (agricultura de corte e queima). Estes dois produtos são plantados tanto em mata primária quanto em capoeira, mas a preferência é sempre pela mata primária, uma vez que ao ser derrubada e preparada para o plantio, a mata primária demora mais para que as espécies pioneiras na regeneração comecem a brotar. Desta forma os produtos agrícolas crescem mais rápido e melhor. Além disto, o tempo de pousio de uma área de capoeira tem que ser maior do que de uma área de mata recém-aberta.

Alguns agricultores das comunidades de terra firme só plantam banana em área de mata primária, alegando que nestas áreas o "mal da banana” (doença que ataca os bananais, matando as plantas) não se prolifera. Para tanto, estes agricultores têm que ir longe, uma vez que as áreas de mata primárias já estão escassas. A média do tempo de pousio das capoeiras nestas comunidades é de 3,4 anos ( $\pm 0,9)$, tempo mínimo que os agricultores julgam necessário para possibilitar o crescimento do plantio, e tempo máximo que podem esperar para replantarem no mesmo local. A média de idade das capoeiras mais antigas dentro dos limites das comunidades é de 7,1 anos ( \pm 5,8), o que reflete o desgaste destas áreas de cultivo.

O tamanho da safra de farinha não diferiu entre comunidades com e sem manejo $(8.750 \mathrm{Kg} / \mathrm{safra} \pm 8.800$ e $8.100 \mathrm{Kg} / \mathrm{safra} \pm 6.350$, respectivamente). Já safra de banana foi maior nas comunidades sem manejo (200 cachos/safra \pm 96$)$ do que nas comunidades com manejo (172 cachos/safra \pm 64$)$ no mesmo ano. A safra de mandioca e banana é bem distribuída durante todo o ano, o que caracteriza a agricultura como uma atividade segura na terra firme, mesmo que não seja muito rentável, principalmente no caso da mandioca.

Com relação ao uso de outros tipos de recursos, a exploração madeireira representava, no passado, a atividade de maior rentabilidade para $11,1 \%$ das famílias nas comunidades de terra firme com manejo, o que atualmente não ocorre, provavelmente pela escassez de madeira na área, provocada principalmente pelo desmatamento para plantio agrícola. Nestas comunidades, a agricultura cresceu em importância de retorno monetário na mesma proporção em que decresceu a importância da exploração madeireira. A Tabela VI apresenta as principais espécies madeireiras exploradas nestas comunidades. 
Tabela VI - Principais espécies madeireiras exploradas nas comunidades de terra firme estudadas, com e sem manejo.

\begin{tabular}{lllcc}
\hline \multirow{2}{*}{ Nome Local } & Gênero/Espécie & Tipo de uso* & \multicolumn{2}{c}{ Tipo de Comunidade } \\
\cline { 3 - 5 } & & & com manejo & com manejo \\
\hline Acapu & Vouacapoua pallidior & Subs. & $\mathrm{X}$ & $\mathrm{X}$ \\
Angelim & Hymenolobium sp. & Subs. & $\mathrm{X}$ & \\
Bacuri & Rheedia brasiliensis & Subs. & & $\mathrm{X}$ \\
Castanheira & Bertholletia excelsa & Subs. & $\mathrm{X}$ & $\mathrm{X}$ \\
Cedrorana & Cedrelingacatenaeformis & Subs. & & $\mathrm{X}$ \\
Cupiuba & Goupia glabra & Subs. & $\mathrm{X}$ & $\mathrm{X}$ \\
Guariúba & Clarisia racemosa & Subs. & & $\mathrm{X}$ \\
Itaúba & Mezilaurus itauba & Subs. & $\mathrm{X}$ & \\
Jacareúba & Calophyllumbrasiliense & Subs. & $\mathrm{X}$ & \\
Jitó & Guareasubssessiliflora & Subs. & $\mathrm{X}$ & \\
Louro Inamui & Ocotea cymbarum & Subs. & $\mathrm{X}$ & $\mathrm{X}$ \\
Louro Preto & Ocotea sp. & Subs. & $\mathrm{X}$ & $\mathrm{X}$ \\
Mulateiro & $\begin{array}{l}\text { Capiromadecorticans } \\
\text { Pãma }\end{array}$ & Subs. & $\mathrm{X}$ & \\
Pajurá & Pseldolmedialaevicarpa & Subs. & $\mathrm{X}$ & \\
\hline
\end{tabular}

* Tipo de uso: subsistência e/ou comercial

A caça sempre foi uma atividade predominantemente de subsistência, sendo desenvolvida de forma comercial apenas por alguns poucos indivíduos em comunidades com manejo, que comercializam a carne de caça na própria comunidade, dentro dos "princípios da preservação", sob fiscalização informal dos comunitários. A Tabela VII apresenta os principais animais caçados nas comunidades de terra firme. 
Tabela VII - Animais de caça explorados nas comunidades de terra firme estudadas, com e sem manejo.

\begin{tabular}{|c|c|c|c|c|c|}
\hline \multirow{2}{*}{$\begin{array}{l}\text { Nome } \\
\text { Local }\end{array}$} & \multirow[b]{2}{*}{ Classe } & \multirow[b]{2}{*}{ Gênero/Espécie } & \multirow{2}{*}{$\begin{array}{c}\text { Tipo de } \\
\text { uso* }\end{array}$} & \multicolumn{2}{|c|}{ Tipo de Comunidade } \\
\hline & & & & $\begin{array}{c}\text { com } \\
\text { manejo }\end{array}$ & $\begin{array}{c}\text { sem } \\
\text { manejo }\end{array}$ \\
\hline Tatu & Mammalia & Dasypus sp. & Subs. & $\mathrm{X}$ & $\mathrm{X}$ \\
\hline Guariba & Mammalia & Alouatta seniculus & Subs. & $\mathrm{X}$ & $\mathrm{X}$ \\
\hline Barrigudo & Mammalia & Lagothrixlagotricha & Subs./Com. & $\mathrm{X}$ & \\
\hline Prego & Mammalia & Cebus albifrons & Subs. & $\mathrm{X}$ & \\
\hline Queixada & Mammalia- & Tayassu pecari & Subs. & $\mathrm{X}$ & $\mathrm{X}$ \\
\hline Cateto & Mammalia & Pecari tajacu & Subs./Com. & & \\
\hline Anta & Mammalia & Tapirus terrestris & Subs. & $\mathrm{X}$ & \\
\hline Veado & Mammalia & Mazama spp. & Subs./Com. & $\mathrm{X}$ & $\mathrm{X}$ \\
\hline Cutia & Mammalia & Dasyproctacristata & Subs. & $\mathrm{X}$ & $\mathrm{X}$ \\
\hline Paca & Mammalia & Cuniculus paca & Subs./Com. & $\mathrm{X}$ & $\mathrm{X}$ \\
\hline Inhambú & Ave & Crypturellus sp. & Subs. & $\mathrm{X}$ & \\
\hline Jacamim & Ave & Psophia creptans & Subs. & $\mathrm{X}$ & \\
\hline Jacu & Ave & Penelope sp. & Subs. & $\mathrm{X}$ & \\
\hline Mutum & Ave & Mitu sp. & Subs. & $\mathrm{X}$ & \\
\hline
\end{tabular}

* Tipo de uso: subsistência e/ou comercial

No período do estudo, verificou-se que a coleta e venda do fruto da castanha do Pará (Bertholletia excelsa) e a criação de gado passaram a ser atividades comerciais complementares à agricultura. A coleta da castanha representou a atividade de maior retorno monetário para 5,3\% e 2,6\% das famílias entrevistadas nas comunidades de terra firme sem manejo e com manejo, respectivamente. Outros produtos não madeireiros também eram coletados e comercializados em menor escala,como os frutos doaçaí(Eutherpeoleracea), dopatauá(Oenocarpus bataua), da bacaba (Oenocarpus distichus) e do buriti (Mauritia flexuosa) (TabelaXI). A coleta da castanha diferiu bastante entre as comunidades com e sem manejo (39 sacas de $50 \mathrm{~kg} / \mathrm{safra} \pm 46$ e $400 \mathrm{sacas}$ de $50 \mathrm{~kg} / \mathrm{safra} \pm 230$ ).

\section{SIMILARIDADES ENTRE COMUNIDADES}

A Figura 2 mostra a análise de agrupamento (cluster analysis) conduzida para comparar as comunidades em relação ao número de registros de atividades econômicas (incluindo agricultura, pesca, caça, exploração madeireira, coleta de produtos não madeireiros vegetal e animal). Observou-se uma tendência de agrupamento das comunidades de várzea sem manejo. A comunidade de "Sao Paulo do Coracy" (Figura 2: var_com_man3) que se localiza na várzea, com manejo, foi considerada a mais bem sucedida no manejo de recursos naturais dentro das 
comunidades estudadas. Isto pode de certa forma explicar a dissimilaridade desta comunidade em relação às outras, apresentadas na análise de cluster (Figura 2). Outro padrão observado na análise foi o grupo de quarto comunidades de terra firme com e sem manejo (Itapiranema - tf s/ man 1, Juruamã - tf s/ man 3, Boa Esperançã do Amanã - tf c/ man 2 and Bela Conquista - tf c/ man 3).

$\mathrm{Na}$ maioria das comunidades estudadas, a percepção de benefícios em relação ao manejo de lagos, pelo menos em curto prazo, permitiu a transformação do modelo originalmente preservacionista em um modelo conservacionista de manejo, baseado no uso dos recursos manejados, e não simplesmente na preservação sem o uso. As comunidades de "São Joaquim" e "Santa Helena do Icé” podem ser citadas como um exemplo de sucesso e posterior declínio do modelo preservacionista de manejo. As regras rígidas de preservação dos lagos manejados por estas comunidades, num período de aproximadamente 18 anos, permitiram um aumento do estoque pesqueiro, principalmente de espécies de alto valor econômico como o pirarucu (Arapaima gigas). Para Santa Helena, a flexibilização das regras para a pesca de subsistência foi suficiente, uma vez que a comunidade é tipicamente agricultora, sendo que a pesca nunca foi uma atividade comercial forte. Mas para a comunidade de "São Joaquim” esta flexibilização não foi suficiente para conter a insatisfação dos comunitários com a rigidez das regras de preservação, uma vez que a comunidade sem foi tradicionalmente de pescadores comerciais. Desta forma após alguns anos de manejo, os próprios comunitários invadiram os lagos, o que acabou incentivando a invasão por comunitários de outras comunidades. 


\section{Análise de Cluster}

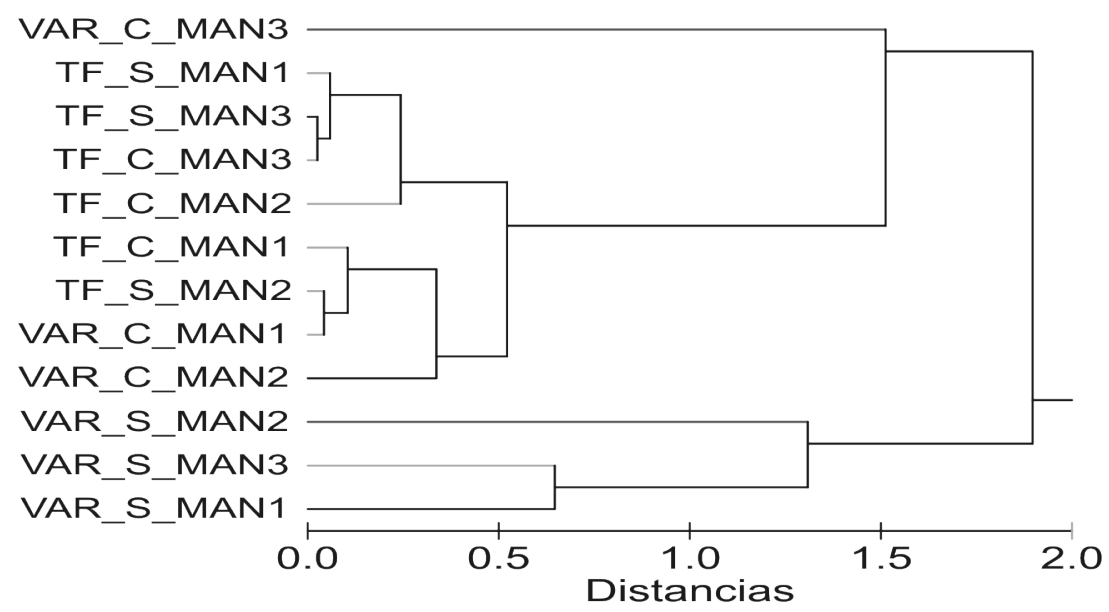

Figura 2 - Análise de agrupamento das comunidades estudadas, com relação ao número de registros de atividades econômicas (incluindo agricultura, pesca, caça, exploração madeireira, coleta de produtos não madeireiros vegetal e animal). Descrição das comunidades: Santa Teresa do Cubuá (var c/ man 1), Santa Helena do Icé (var c/ man 2), São Paulo do Coracy (var c/ man 3), Santa Rosa (var s/ man 1), São Joaquim (var s/ man 2), Ebenézer (var s/ man 3), Santa Luzia do Catuiri (tf c/ man 1), Boa Esperançã do Amanã (tf c/ man 2), Bela Conquista (tf c/ man 3), Itapiranema (tf s/ man 1), Bom Jesus do Baré (tf s/ man 2) e Juruamã (tf s/ man 3).

A comunidade de São Paulo do Coracy pode ser citada como um exemplo da transformação do modelo preservacionista em conservacionista que favoreceu a continuidade e fortalecimento da iniciativa de manejo de lagos. A flexibilização das regras nesta comunidade favoreceu não só à pesca de subsistência mas também as pescas comerciais individuais, desenvolvidas nos lagos manejados em acordo com a comunidade, em situações de emergência. O benefício, principalmente monetário, decorrente do manejo, caracterizou um grande incentivo á conservação dos lagos e cumprimento das regras do manejo por parte dos comunitários.

Já na comunidade de Santa Teresa, a falta de percepção de benefícios monetários advindos do manejo de lagos provavelmente incentivou à comunidade a realizar outras atividades econômicas, como a intensificação da agricultura, que provocou um drástico aumento na retirada de cobertura vegetal.

A Figura 3 mostra a análise de agrupamento das comunidades estudas em relação à riqueza de espécies de peixes exploradas. Observa-se uma tendência ao agrupamento de comunidades de várzea com e sem manejo em dois grupos diferentes. Também as comunidades de terra firme com e sem manejo foram agrupadas em dois grupos diferentes, embora a comunidade de Juruamã (tf 
s/ man3) tenha permanecido mais próxima das comunidades com manejo, provavelmente pela presença de um açude artificial próximo, utilizado pela comunidade para a pesca em ocasiões eventuais.

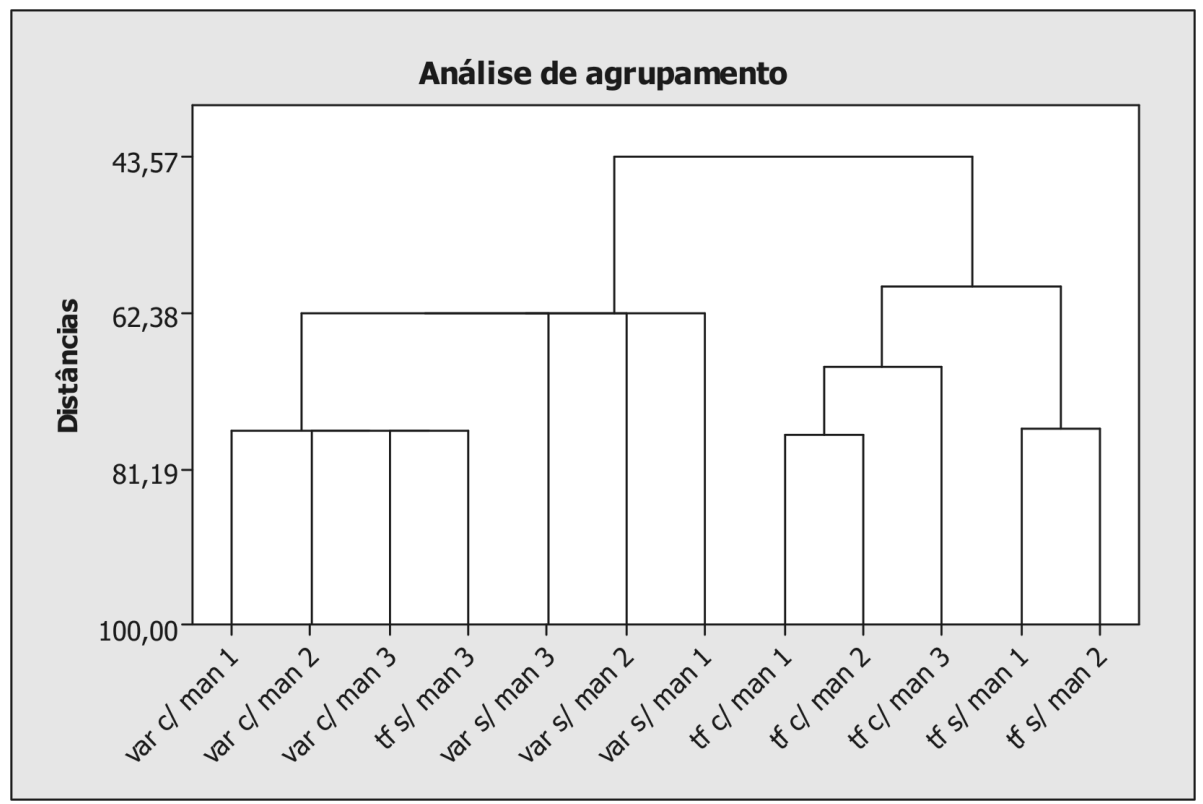

Figura 3 - Análise de agrupamento das comunidades em relação à riqueza de espécies de peixes exploradas. Descrição das comunidades: Santa Teresa do Cubuá, floodplain with management (var c/ man 1), Santa Helena do Icé (var c/ man 2), São Paulo do Coracy (var c/ man 3), Santa Rosa (var s/ man 1), São Joaquim, (var s/ man 2), Ebenézer (var s/ man 3), Santa Luzia do Catuiri (tf c/ man 1), Boa Esperançã do Amanã (tf c/ man 2), Bela Conquista (tf c/ man 3), Itapiranema (tf s/ man 1), Bom Jesus do Baré (tf s/ man 2) e Juruamã (tf s/ man 3).

\section{PERCEPÇÕES SOBRE MUDANÇAS NOS RECURSOS NATURAIS}

Em relação aos animais de caça, a maioria dos entrevistados nas comunidades sem manejo, tanto de várzea $(60 \%)$ quanto de terra firme $(80 \%)$ acreditam que este recurso está mais escasso no presente do que no passado, principalmente nas comunidades de terra firme, onde o desmatamento para cultivo agrícola foi maior, provocando o afastamento dos animais de caça. $\mathrm{O}$ mesmo ocorreu nas comunidades de terra firme com manejo, onde mais de 60\% dos entrevistados acreditam que os animais de caça estão mais escassos do que no passado, além disto, mais de $80 \%$ dos entrevistados, nestas comunidades, não acham que o processo de manejo teve alguma influência sobre este recurso específico. Sobre os dados de caça comparados entre comunidades de terra firme com e sem manejo, não houve diferença estatística significativa (Test $G=3,11$; gl $=2$; ( $p$ ) $=0,2)$. O efeito do manejo em relação aos animais de caça nas comunidades de 
terra firme não foi percebido pelos moradores, se assemelhando às percepções de escassez dos animais de caça em comunidades que não desenvolvem manejo. Nas comunidades de várzea com manejo, mais de $60 \%$ dos entrevistados acreditam que os animais de caça estão mais abundantes do que no passado, e 58,6\% acham que o manejo teve influência direta sobre esta mudança. A influência do modelo de manejo integrado nas comunidades filiadas ao GPD influenciou a introdução de regras informais de caça, pelas comunidades. Entre estas regras estão: a não comercialização indiscriminada de animais de caça pelos comunitários, a redução do número de animais caçados por comunitário, mesmo que seja para subsistência e a proibição da atividade de caça por pessoas de fora da comunidade dentro dos limites da mesma.

Na comparação entre as comunidades de várzea com e sem manejo, verificase uma diferença significativa na porcentagem dos registros de maior abundância dos animais de caça (Test $G=109,1 ; \mathrm{gl}=2 ;(\mathrm{p})=0,000)$, o que significa que provavelmente o manejo integrado de recursos adotados nestas comunidades de várzea, tem propiciado a percepção no aumento dos animais de caça, o que não tem ocorrido nas comunidades de várzea que não desenvolvem manejo, provavelmente em decorrência da escassez deste recurso.

As diferenças de percepções relacionadas ao pescado foram bastante expressivas. Nas comunidades de várzea com manejo, mais de $95 \%$ dos entrevistados acham que os peixes estão mais abundantes atualmente e $87 \%$ acreditam que o manejo é o grande responsável por esta mudança. Já nas comunidades de terra firme com manejo 70\% dos entrevistados acreditam que o pescado está mais escasso atualmente, do que antes do início do manejo. Comparando estatisticamente as comunidades de várzea e terra firme com manejo, verifica-se que existe diferença significativa em relação aos registros (Teste $G=71,4 ; g l=2 ;(p)=0,000$ ), o que significa que os efeitos do manejo não tem sido percebidos em termos do aumento do pescado nas comunidades de terra firme que adotaram o modelo de manejo. Apesar de parecer uma projeção pessimista, pouco mais de $60 \%$ dos comunitários entrevistados acreditam que a preservação ainda teve influência, pois sem ela, a situação do estoque pesqueiro poderia estar pior.

Nas comunidades sem manejo, tanto de terra firme quanto de várzea, onde não existe nenhum processo de preservação, 100\% dos entrevistados acham que o estoque pesqueiro está mais escasso do que no passado. Os únicos motivos apontados como causa desta percepção é a pressão externa (por peixeiros) e interna (dos próprios comunitários) sobre o recurso, que talvez pudesse ser contornada com a adoção do manejo. 
Impactos ecológicos do manejo comunitário de recursos naturais em comunidades ribeirinhas de várzea e terra firme na região de Tefé, AM

Sobre as espécies madeireiras, nas comunidades sem manejo, tanto de terra firme $(85 \%)$ quanto de várzea (70\%), a maioria dos entrevistados acredita que as madeiras estão mais escassas hoje do que no passado. Nas comunidades de terra firme a causa para este resultado parece ser além da pressão de exploração madeireira na região, o desmatamento para áreas de cultivo agrícola. Nas comunidades de várzea este desmatamento é desenvolvido em menor escala, pois áreas de mata baixa, onde predominam espécies madeireiras importantes, não são apropriadas para agricultura, por permanecerem inundadas boa parte do ano. Apesar destas áreas sofrerem com a exploração madeireira ainda nos dias de hoje.

Nas comunidades de terra firme com manejo $90 \%$ dos entrevistados acham que as espécies madeireiras estão mais escassas, pelos mesmos motivos descritos para as comunidades de terra firme sem manejo (pressão de exploração madeireira e o desmatamento para cultivo agrícola). Já nas comunidades de várzea com manejo o resultado foi bem diferente, $97 \%$ acreditam que as espécies madeireiras estão mais abundantes e 89,6\% acham que a preservação (manejo) teve influência sobre esta mudança.

Também neste caso, o modelo de manejo integrado incentivou a criação de regras informais em relação aos recursos madeireiros, mas, além disto, o aumento da fiscalização do IBAMA sobre a atividade de exploração madeireira na região, também contribuiu para a percepção do aumento deste recurso. Dentre as regras informais incorporadas pelas comunidades de várzea filiadas ao GPD estão: a proibição da exploração madeireira para comercialização dentro da área das comunidades, tanto para os próprios comunitários, quanto para pessoas de fora da comunidade; o plantio de mudas de espécies madeireiras de importância comercial em áreas de mata; e evitar corte de mudas e/ou árvores adultas de grande importância comercial, nas áreas abertas para cultivo agrícola.

Dentro dos dados coletados sobre percepção em relação aos recursos naturais, através dos questionários, foi considerado também a questão da falta de áreas para o cultivo agrícola. Não houve diferença significativa entre a percepção de falta de áreas para o cultivo agrícola entre comunidades de terra firme com e sem manejo (Teste $\mathrm{G}=0,2 ; \mathrm{gl}=1 ;(\mathrm{p})=0,60)$, nem nas comunidades de várzea com e sem manejo (Teste $\mathrm{G}=0,00 ; \mathrm{gl}=2 ;(\mathrm{p})=1,00)$. Mas a diferença é significativa quando comparamos os dados entre comunidades de várzea e terra firme, sem manejo (Teste $\mathrm{G}=45,0 ; \mathrm{gl}=2 ;(\mathrm{p})=0,00)$. Apesar de não verificarmos esta diferença entre as comunidades de várzea e terra firme com manejo (Teste $\mathrm{G}=1,4 ; \mathrm{gl}=2$; $(p)=0,48)$, os dados indicam que neste caso, as diferenças de percepções sobre a falta de áreas para o cultivo agrícola, não podem ser explicadas pela influência do modelo de manejo, mas sim pela própria natureza dos ecosssistemas. 


\section{DISCUSSÃO}

Verificou-se que a natureza dos ecossistemas estudados influenciou sobre o êxito no processo de manejo. As regras de acesso e estratégias de uso propostas dentro de um sistema de manejo devem ser compatíveis com as características ecológicas do ecossistema onde o manejo será implantado. Neste estudo de caso, verificou-se que o modelo original de manejo de lagos era mais compatível à realidade do ecossistema de várzea.

As estratégias agrícolas utilizadas nas comunidades de várzea foram semelhantes às utilizadas em terra firme, sendo a agricultura de corte e queima a estratégia predominante e a base dos produtos cultivados sendo a banana e a mandioca, para produção artesanal da farinha. Entretanto, a dinâmica de plantio e safra diferiu bastante da terra firme, por causa das características ecológicas e sazonais da várzea. Nas comunidades da várzea, o plantio é feito somente nas áreas de restinga, onde a terra é mais alta. Teoricamente, as áreas para cultivo agrícola nestas comunidades são bem menos extensas que as da terra firme, e a época de colheita é reduzida, geralmente ocorrendo apenas uma colheita por ano, que coincide com a época da enchente entre os meses de março e junho, já que o plantio era feito na época da vazante. O tempo de pousio no ecossistema da vázea, pode ser bem menor do que na terra firme, já que o desgaste da terra é amenizado pela renovação de nutrientes proporcionada pelas cheias anuais.

É importante salientar que, tanto no passado quanto no presente, a agricultura sempre foi a atividade de maior importância em relação ao retorno monetário para mais de $80 \%$ das famílias nas comunidades de várzea com manejo. Já nas comunidades sem manejo, apesar de também apresentarem uma redução da pesca enquanto atividade comercial, ela continua sendo um fator de retorno monetário importante. Os pescadores destas comunidades, por não terem se envolvido em nenhuma iniciativa de manejo dos lagos próximos às suas áreas de moradia, enfrentam uma alta competição com outros usuários e têm sido obrigados a ir buscar o peixe cada vez mais longe, tornando a atividade cada vez mais irregular do ponto de vista econômico. Esta instabilidade é, na maioria das vezes, compensada pela agricultura, que no caso da várzea é sazonal e em alguns momentos tão arriscada quanto a pesca. Um exemplo disto ocorreu em 1999, quando a cheia foi tão grande que inundou áreas de restingas altas, praticamente exterminando a plantação de bananas, inclusive as mudas, da maioria das comunidades de várzea da região.

O declínio dos estoques pesqueiros atingiu comunidades de várzea e de terra firme, forçando uma mudança de estratégia de uso dos recursos ao longo do tempo 
Impactos ecológicos do manejo comunitário de recursos naturais em comunidades ribeirinhas de várzea e terra firme na região de Tefé, AM

na região do Médio Solimões (Costa et al., 1999). As comunidades que adotaram o modelo de manejo de lagos dependiam menos da atividade de pesca comercial do que as comunidades não filiadas ao GPD, sem manejo. Mas nas comunidades com manejo, a queda na atividade de pesca destinada à comercialização em relação ao passado foi maior do que nas comunidades sem manejo. Isto sugere a soma de outro fator limitante que não só a escassez do recurso, mas também a forma preservacionista do manejo, introduzido por estas comunidades, que desestimulava o uso comercial do pescado em seus lagos. Mesmo após o expressivo aumento do estoque pesqueiro nos lagos, em decorrência do processo de manejo, as comunidades continuaram a não usufruir comercialmente do recurso como faziam antes da preservação.

Observou-se neste estudo que nas comunidades da região onde a pesca era a atividade econômica mais desenvolvida, não estavam envolvidas no modelo de manejo, que foi difundido em toda a região. Justamente onde a pressão sobre a pesca sempre foi maior, o modelo de manejo não foi absorvido, provavelmente pelo seu caráter preservacionista de incentivo ao não uso do recurso pesqueiro nos lagos manejados.

A falta de uso dos lagos manejados pode ter incentivado a invasão por usuários de fora da comunidade. $\mathrm{O}$ aumento no estoque pesqueiro acabou servindo como chamariz para os invasores comerciais da região. O próprio uso do lago pelas comunidades que os manejam, mesmo que seja esporádico, implica em maior controle e fiscalização por parte dos próprios manejadores. A fiscalização também pode ser feita no caso de não uso dos lagos, mas desta forma, implica também em aumento de custo no processo de manejo. Algumas comunidades, principalmente as que conseguiram portarias do IBAMA para controle da pesca em seus lagos, acabaram confiando a vigilância dos lagos aos órgãos do governo e tiveram seus lagos invadidos e seus estoques pesqueiros arrasados. Portanto, a fiscalização pelos próprios comunitários estava sendo mais eficiente enquanto utilizam os lagos manejados e acompanham qualquer movimentação de outros usuários no local. A fiscalização pelos comunitários funcionava através de conversas, no caso de invasores de subsistência e até apreensão de materiais de pesca, no caso de invasores comerciais, se houvesse resistência.

O ponto crítico em relação ao manejo comunitário de lagos incentivado pelo GPD na região de Tefé, e que colocava em risco a viabilidade do modelo, seja ele preservacionista ou conservacionista era a incerteza da sustentabilidade dos recursos. Este modelo de manejo teve origem com a atuação da Igreja Católica na formação das comunidades, e desde o início este processo de manejo não teve nenhum tipo de apoio técnico científico nem financeiro. Cunha (2002) 
denomina este modelo de intervenção como sendo local-autônomo, onde existiu uma intervenção e mediação por parte da Igreja, mas a autonomia do processo ficou a cargo das próprias comunidades manejadoras, inclusive a transformação do modelo original.

A definição de um modelo de manejo simples cumpriu duas funções dentro do processo: facilitou as atividades de monitoramento e não requereu conhecimento técnico ou inversão de recursos financeiros externos para sua implementação. As comunidades, assim, puderam desenvolver certo grau de autonomia na gestão de suas iniciativas de manejo dos lagos. Esta autonomia levou a transformações do modelo geral e a adaptações pelas comunidades aos desafios e às oportunidades que se lhes apresentavam. A autonomia das comunidades sobre o processo de manejo deve ser vista, em alguns momentos, como fator fundamental no sucesso destas iniciativas.

$\mathrm{Na}$ continuidade do processo e sobre a ótica ecológica, o modelo localautônomo estudado pode ser alvo de algumas críticas. A sustentabilidade do recurso não tem sido atestada ao longo destes anos de manejo, justamente pela falta de apoio técnico científico no processo. Não se pode desconsiderar, por exemplo, a percepção das comunidades de várzea em relação ao aumento do estoque pesqueiro nos lagos manejados, por outro lado, e até mesmo de forma contraditória, esta percepção tem sido baseada principalmente na presença de grandes quantidades de peixe com alto valor comercial, como o pirarucu (Arapaima gigas) e o tambaqui (Colossoma macropomum). Eram estas as espécies mais pressionadas pela pesca predatória e o aumento da quantidade destes peixes confirma, para os comunitários, a validade de seus esforços em manejar os lagos.

Diversas comunidades rurais na Amazônia têm se envolvido em experiências de manejo comunitário, sobre diversos tipos de mediação; mas os impactos ecológicos e a sustentabilidade ecológica destas iniciativas têm sido pouco estudados, entretanto, o potencial destas comunidades em promover a conservação dos recursos naturais é grande, se aliado a um suporte técnico científico que possa adequar as iniciativas das comunidades à sustentabilidade dos recursos.

\section{REFERÊNCIAS BIBLIOGRÁFICAS}

ANDERSON, A. B.. 1990. Deforestation in Amazonia: dynamics, cause, and alternatives. In: Alternatives to deforestation: steps toward sustainable use of the Amazon rain Forest (ed: Anthony B. Anderson), Columbia University Press, New York. 
Impactos ecológicos do manejo comunitário de recursos naturais em comunidades ribeirinhas de várzea e terra firme na região de Tefé, AM

AYRES, J. M.; AYRES JR, M.; AYRES, D.; SANTOS, A.S.. 2000. BIOESTAT 2.0: aplicações estatísticas nas áreas das ciências biológicas e médicas. Sociedade Civil Mamirauá, CNPq, Brasília.

AYRES, J. M.. 1995. As Matas de Várzea do Mamirauá. Conselho Nacional de Desenvolvimento Científico e Tecnológico, Sociedade Civil Mamirauá, Tefé, AM.

BARTHEM, R.. 1999. A pesca comercial no Médio Solimões e sua interação com a reserva Mamirauá. In: Estratégias para manejo de recursos pesqueiros em Mamirauá. (Eds. Helder Queiroz e William Crampton), MCT, CNPq, Sociedade Civil Mamirauá, Belém, Pará, pp 72 - 107.

CAMPOS, M. T. ; NEPSTAD, D. C.. 2006. Smallholders, the Amazon new conservationists. Conservation Biology, v. 20, p. 1553-1556.

BECKER, B. K.. 2001. A síntese do processo de ocupação da Amazônia - Lições do passado e desafios do presente. In: Causas e dinâmica do desmatamento na Amazônia, Ministério do Meio Ambiente, Brasília.

ALMEIDA, O. T. ; LORENZEN, K. ; MCGRATH, D.. 2009. Fishing agreements in the lower Amazon: for gain and restraint. Fisheries Management and Ecology, v. 16, p. 61-67.

BARTHEM, R. B.. 1987. Uso de Redes de Espera No Estudo de Ritmos Circadianos de Algumas Especies de Peixes Nos Lagos de Varzea do Rio Solimoes. Revista Brasileira de Zoologia, v. 3, n. 7, p. 409-422.

BARTHEM, R. B. ; GOULDING, M.. 1997. Os Bagres Balizadores: Ecologia, Migração e Conservação de Peixes Amazônicos. Brasília: Sociedade Civil Mamirauá; Brasília: CNPq; Manaus, AM: Instituto de Proteção Ambiental do Estado do Amazonas. 140 p.

BARTHEM, R. B.. 1999. A Pesca Comercial no Médio Solimões e sua Interação com a Reserva de Desenvolvimento Sustentável Mamirauá. In: Helder L. Queiroz; Willliam G. R. Cramp. (Org.). Estratégias para Manejo de Recursos Pesqueiros em Mamirauá. Brasília: Sociedade Civil Mamirauá e CNPq, v. , p. 72-107.

BENATTI, J.H.; MCGRATH, D.G.; OLIVEIRA, A.C.M.. 2003. Políticas Públicas e manejo comunitário de recursos naturais da Amazônia. Ambiente e Sociedade VI(2): 137 a 154.

CASTRO, F. E MCGRATH, D. 2001. O manejo comunitário de lagos na Amazônia. Parcerias Estratégicas v 12: 112-126. 
CASTRO, F.; MCGRATH, D.; CROSSA, M.. 2002. Adaptándose A Los Cambios: La Habilidad De Las Comunidades Ribereñas En El Manejo De Sistemas De Lagos De La Amazonia Brasileña. In Smith, R. C. e Pinedo, D. (Eds). Nuestros bosques, nuestros lagos: la gestión comunitaria de los bienes comunes en la Amazonía. Lima, Instituto del Bien Común \& Insituto de Estudios Peruanos.

COSTA, L. R. F.; BARTHEM, R. B.; CORREIA, M. A. V.. 1999. Manejo da pesca do tambaqui nos lagos de várzea da Reserva de Desenvolvimento Sustentável Mamirauá. In: Helder L. Queiroz; Willliam G. R. Cramp. (Org.). Estratégias para Manejo de Recursos Pesqueiros em Mamirauá. Brasília: Sociedade Civil Mamirauá e CNPq, p. 142-158.

CUNHA, L. H. H.. 2002. Manejo Comunitário de Recursos Naturais na Amazônia: Arranjos Institucionais e Mediação Externa. Tese de Doutorado, Programa de Pós Graduação em Desenvolvimento Sustentável do Trópico Umido, Núcleo de Altos Estudos Amazônicos, UFPA, Belém, PA. 196 p.

CUNHA, M. C. ; ALMEIDA, M. W.B.. 2001. Populações tradicionais e conservação Ambiental. In: Biodiversidade na Amazônia Brasileira (ed. João Paulo Capobianco), Imazon, IPAM, ISPN, GTA, CI e ISA. Pp: $184-199$.

FAULHABER, P.. 1987. Estrutura fundiária e movimentos territoriais no Médio Solimões. Bol. Mus. Par. Emílio Goeldi, serie Antropología, 3 (1), pp. 79 97.

HENDERSON, P. A.. 1999. O ambiente aquático da Reserva Mamirauá. In: Estratégias para manejo de recursos pesqueiros em Mamirauá. (Eds. Helder Queiroz e William Crampton), MCT, CNPq, Sociedade Civil Mamirauá, Belém, Pará, pp 01 - 09.

LIMA, E. ; MERRY, F ; NEPSTAD, D. C. ; AMACHER, G. S. ; AZEVEDORAMOS, C. ; LEFEBVRE, P ; RESQUE JR., F.. 2006. Searching for sustainability: forest policies, smallholders, and the Trans-Amazon highway. Environment (St. Louis), v. 48, p. 26-38.

MCGRATH, D. G.; CASTRO, F.; FUTEMMA, C.; DOMINGUES, B.; CALÁBRIA, J.. 1993. Fisheries and the Evolution of Resource management on the Lower Amazon Floodplain. Human Ecology, 21(2), pp 167 - 195.

McGRATH, D. G.. 1998. Biosfera ou biodiversidade: uma avaliação crítica do paradigma da biodiversidade. In: Perspectivas do desenvolvimento sustentável (uma contribuição para a agenda 21) (ed: Tereza Ximenes), NAEA, Universidade Federal do Pará, Belém, Pará. 
MCGRATH, D.; ALMEIDA, O. T. ; MERRY, F. D.. 2007. The Influence of Community Management Agreements on Household Economic Strategies : Cattle Grazing and Fishing Agreements on the Lower Amazon Floodplain. International Journal of the Commons, v. 1, p. 67-88.

PIRES, J. M.. 1973. Tipos de vegetação da Amazônia. Publicações Avulças do Museu Goeldi, Belém, 20: 179-202.

PRANCE, G. T.. 1978. The origin and evolution of the Amazon flora. Interciencia, 3: 207-230.

QUEIROZ, H. L. (Org.) ; CRAMPTON, W. (Org.) . Estratégias Para Manejo dos Recursos Pesqueiros em Mamirauá.. Brasília, DF: SCM, CNPq/MCT, 1999. 208 p. 